\title{
Строение и морфология ледникового рельефа в бассейне р. Кица (Умбозерская)
}

\author{
Вашков А.А. ${ }^{1}$ Носова О.Ю. ${ }^{1}$, Колька В.В. ${ }^{1}$, Толстобров Д.С. ${ }^{1}$, Костромина Н.А. ${ }^{2}$, \\ Крикунова А.И. ${ }^{2}$, Крошинский В.А. ${ }^{3}$ \\ 1 Геологический институт КНЦ РАН, Anamumbl,vashkov@geoksc.apatity.ru \\ 2 Санкт-Петербургский государственный университет, Санкт-Петербург \\ 3 Государственное предприятие «НПЦ по геологии», филиал «Институт геологии», Минск, \\ Республика Беларусь
}

Аннотация. В статье рассмотрены вопросы строения и морфологии аккумулятивного рельефа в центральной части Кольского региона. Установлена ведущая роль чешуйчатых, диапировых и складчатых гляциодислокаций в строении форм ледникового генезиса. Определены закономерности пространственного расположения и морфологические характеристики форм рельефа, соответствующие гляциодислокациям разного типа. Сделан вывод о развитии в районе работ трех цепочек краевых образований, соответствующих отдельным фазам деградации последнего ледникового покрова в позднем плейстоцене. Полученные данные имеют большое значение для установления особенностей динамики северного сектора беломорского ледникового потока, а также могут быть использованы в виде критериев прогнозирования минерально-строительного сырья.

Ключевые слова: краевые образования, гляциодислокация, диапир, базальный тилл, флювиогляциальные отложения, озерно-ледниковые отложения, моренная гряда.

\section{Composition and morphology of glacial relief in the basin of the Kitsa River (the Umbozero Lake area)}

\author{
Vashkov A.A., Nosova O.Yu., Kolka V.V., Tolstobrov D.S., Kostromina N.A., Krikunova A.I., \\ Kroshinskii V.A. \\ ${ }^{1}$ Geological Institute of Kola Scientific Centre of RAS, Apatity,vashkov@geoksc.apatity.ru \\ ${ }^{2}$ Saint Petersburg State University, Saint Petersburg \\ ${ }^{3}$ State Enterprise «Research and Production Centre for Geology», Branch «Institute of Geology», Minsk, \\ Belarus
}

\begin{abstract}
In the article the issues of composition and morphology of accumulative relief in the central part of the Kola region are considered. The main role in composition of the glacial forms is determined to belong to squamous, diapir and folded glaciodislocations. Regularities of spatial arrangement and morphological characteristics of the relief forms, which correspond to glaciodislocations of different types, have been defined. It is concluded that three rows of marginal formations corresponding to individual retreat stages of the last glacial cover in the Late Pleistocene were developed on the studied area. Obtained data are important to determination of dynamic features of the north sector of the White Sea Ice Stream. Moreover, they may be used as criteria to prediction of mineral-building materials.

Key words: marginal formations, glaciodislocations, diapir, lodgement till, fluvioglacial deposits, limnoglacial deposits, moraine ridge.

\section{Введение}

Одним из наиболее сложных участков развития краевых ледниковых образований на Кольском полуострове является район между Ловозерскими, Панскими Тундрами, южной частью озера Умбозеро и Мунозерской возвышенностью. В ходе полевых работ 2018 года был обследован западный участок этого сектора, западнее Фёдоровой Тундры, в бассейне р. Кица (умбозерская). Генезис грядового, грядово-холмистого и холмистого рельефа участка работ имеет разные интерпретации. Первоначально он относился к территории распространения холмистой моренной равнины и не сопоставлялся с краевыми образованиями (Лаврова, 1960). Позже рельеф участка относился к внутренней зоне ледникового покрова с краевыми образованиями на склонах Панских Тундр (Стрелков и др., 1976, Евзеров и др., 1980). Новый фактический материал, полученный геологическим институтом Кольского научного центра и Мурманской геолого-разведочной экспедицией по-
\end{abstract}


зволил выявить в районе работ серию напорных моренных гряд, радиальных озов, участки развития грядово-холмистого моренного рельефа и отдельные холмы - гляциодиапиры (Евзеров и др., 1993, 2000). С этого времени описанные формы рельефа относятся к краевой зоне последнего оледенения, которые, по мнению некоторых исследователей, соотносится со стадией Салпаусселькя I (Ekman at al., 1991). Существует версия о разном возрасте краевых гряд района. Согласно этой версии, ледниковые аккумуляции относятся к внутренней полосе насыпных конечно-моренных образований маргинального пояса II, но западная часть района работ является внешним поясом напорных конечно-моренных гряд более молодого пояса I (Евзеров и др., 1993, 2000). Существуют и современные мнения о том, что район работ относится к моренной равнине внутренней зоны краевых образований невской стадии последнего оледенения (Государственная геологическая карта.., 2012).

\section{Характеристика района исследований}

Кристаллический фундамент района работ представлен породами зоны Имандра - Варзуга: риолито-дацитами, андезитами, базальтовыми порфиритами сейдореченской свиты нижнего протерозоя. В северной части развиты гранодиориты и граниты Центрально-Кольского комплекса верхнего архея. На востоке района расположен высоко приподнятый блок, построенный перидотитами, пироксенитами и габбро-норитами комплекса Фёдоровой Тундры (Геологическая карта.., 2001). Коренные породы повсеместно перекрыты чехлом четвертичных отложений мощностью от 0-10 м в пределах массива Фёдоровой Тундры до 25-50 м в северо-западной части района работ у котловины Умбозера (Государственная геологическая карта.., 2012). В структуре четвертичной толщи установлены ледниковые, озерно-ледниковые и флювиогляциальные аккумуляции, перекрытые современными болотными, озерными и речными осадками. Ледниковые аккумуляции представлены главным образом базальным и абляционным тиллом мощностью 1-5 м и более. Широкое распространение в районе работ имеют озерно-ледниковые аккумуляции средневалдайского возраста (Евзеров и др., 1980). Флювиогляциальные аккумуляции надстраивают толщи тиллов, а также входят в состав конечно-моренных образований.

\section{Методика работ}

В ходе исследования геологическими методами было изучено 10 искусственных обнажений: карьеры, расчистки на склонах гряд, шурфы (рис.1, А). Проводилось подробное изучение структурно-текстурных особенностей: отмечался цвет, гранулометрический состав, текстуры и наличие отдельных слоёв, линз, вкраплений в ледниковых и водно-ледниковых отложениях. Для подтверждения генезиса и определения направлений нагнетания обломочного материала ледником применялся структурный метод массовых замеров плоскостных (плоскости сланцеватости, слоистости) и линейных (длинные оси галек и валунов) элементов тилла (Аболтиньш, 1989). Геоморфологические методы заключались в сопоставлении геологических данных с формами рельефа, а также в морфометрических исследованиях форм рельефа и геомофологическом профилировании.

\section{Полученные результаты}

В строении четвертичной толщи было установлено широкое участие чешуйчатых, диапировых и складчатых гляциодислокаций. Чешуйчатые гляциодислокации имеют мощность свыше 5-8 м и представляют собой отдельные крупные холмистые массивы, гряды и холмы. Типичное строение выявлено в карьере у 62-го километра дороги Октябрьский - 100-ый километр (рис.1, А-2а), который вскрывает полосу холмисто-грядового рельефа, ориентированную с северо-запада на юговосток, длиной 1.6-1.8 км, шириной 0.6-0.7 км. Здесь, под покрышкой абляционного тилла сползания, вскрыты ледниковые аккумуляции, залегающие в виде двух чешуй общей мощностью свыше 5 м (рис. 1, В, D). Верхняя чешуя состоит из базального тилла с включениями и линзами лимногляциальных осадков из тонких песков, алевритов, супесей. Чешуя падает по азимуту $220-245^{\circ}$ под углами 20-29 . Нижняя чешуя представлена преимущественно флювиогляциальными отложениями с прослоями лимногляциальных алевритов и супесей, падение этих пород фиксируется под углом в $10-14^{\circ}$ и по азимуту $300-310^{\circ}$. Контакт двух чешуй прослеживается по прослою базального тил- 


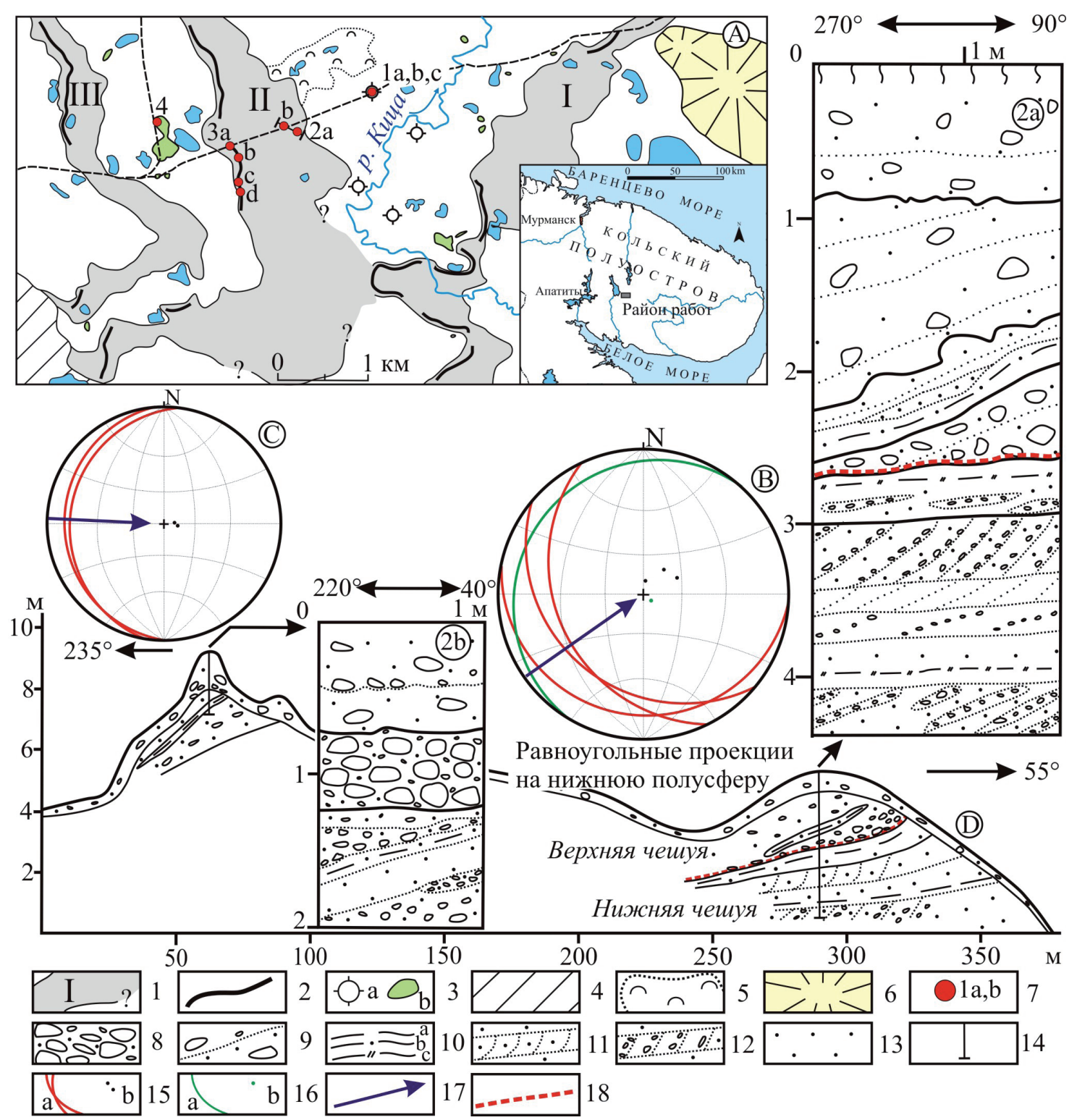

Рис. 1. Гляциоморфологическая схема района работ (А) и строение чешуйчатых гляциоструктур грядово-холмистого рельефа.

Для гляциоморфологической схемы: 1 - полосы грядово-холмистого рельефа, с номерами; 2 - моренные гряды; 3 - гляциодиапиры (а) и флювиокамы (b); 4 - ледораздельная возвышенность (по Колька, 1998); 5 - грядово-кольцевой рельеф мертвого льда; 6 - крупные поднятия кристаллического фундамента; 7 - разрезы, с номерами. Для разрезов и диаграмм: 8 - абляционный тилл; 9 - базальный тилл; 10 - суглинок (a), супесь (b), алеврит (c); 11 - пески мелкозернистые, слоистые; 12 - песчано-гравийная смесь слоистая; 13 - пески разнозернистые; 14 - положение расчисток на разрезе; 15 - плоскости (a) и полюса падения (b) слоистости базального тилла; 16 - плоскость (а) и полюс падения (b) флювиогляциальных отложений; 17 - направление давления ледника; 18 - контакт чешуй в разрезе карьера.

Fig. 1. Glaciomorphological scheme of the study area (A) and composition of the squamous glaciostructures of the ridge-hill relief.

To the glaciomorphological scheme: 1 - bands of the ridge-hill relief, with numbers; 2 - moraine ridges; 3 -glaciodiapirs (a) and fluvioglacial kames (b); 4 - ice-divide upland (by Kolka, 1998); ridge-ring relief of dead ice; 6 - large lifts of bedrock; 7 - sections, with numbers. To the sections and diagrams: 8 - ablation till; 9 - lodgement till; 10 - loam (a), sandy loam (b), silt (c); 11 - fine-grained laminated sands; 12 - laminated sand-gravel mix; 13 - various-grained sands; 14 - location of outcrops on the section; 15 - planes (a) and poles of dip (b) of lodgement till lamination; 16 - plane (a) and pole of dip (b) of fluvioglacial deposits; 17 - ice pressure direction; 18 - contact of the squama in the section of quarry. 
ла, перенасыщенного крупнообломочным материалом. Различие в условиях залегания чешуй может свидетельствовать об изменении направления напора ледника с юго-восточного на восточное и северо-восточное. Нижняя чешуя, при этом, деформирована незначительно, о чем свидетельствует хорошая сохранность первичной слоистости флювиогляциального материала. Чешуйчатое строение характерно и для отдельных небольших холмов (рис. 1, A-2b). Так, в обнажении в 0.7 км к северо-западу от описанного выше разреза в строении холма диаметром до 60 м выявлен базальный тилл с линзами флювиогляциального песчано-гравийно-галечного материала. Падение линз зафиксировано по азимуту $268-279^{\circ}$ и под углами $10-15^{\circ}$ (рис. $\left.1, \mathrm{C}, \mathrm{D}\right)$.

Гляциодиапиры развиты на участке между двумя фронтальными зонами краевых образований и тяготеют к обширному заболоченному понижению с современной долиной р. Кица (умбозерская). В рельефе гляциодиапиры выражены в виде овальных в плане холмов высотой от 5-8 до 15-18 м. Один из таких холмов срезан выемкой дороги Октябрьский - 100-ый километр (рис. 1-1a, b, c). На стенках выемки были заложены три расчистки. В расчистках на северной стенке выемки, вскрывающих центральную часть холма, под толщей абляционного и базального тиллов мощностью 2 м, вскрыты лимногляциальные аккумуляции в виде песков мелкозернистых с редкими зернами гравия и гальки, а также супесей с тонкими прослойками суглинка. Эти же отложения вскрываются по дну выемки, их общая мощность превышает 6 м. Контакт песков и супесей, а также слоистость внутри озерно-ледниковых слоев круто падает по азимуту $210-230^{\circ}$ под углами 40-90. В расчистке на южной стенке выемки (высота заложения на 2.5 м ниже) лимногляциальные осадки не выявлены. Кровля этих отложений, таким образом, образует куполообразное поднятие в центральной части холма, что объясняется пластичной деформацией и последующим нагнетанием материала в относительно ослабленную зону нижней части ледника.

Складчатые деформации установлены в разрезах моренных гряд в виде складок качения и продольного изгиба пород базальных тиллов и подстилающих их водно-ледниковых отложений. Как правило, складки заметны по деформациям линз флювиогляциальных разнозернистых песков и песчано-гравийных смесей, а также супесей и суглинков лимногляциальных. Так, в разрезе моренной гряды длиной до 1-1.8 км, шириной 0.1-0.25 км с крутыми склонами и уплощенной вершиной (расположенной в 0.8 км, восточнее оз. Каменистое) нижнюю часть базального тилла нарушает ряд лежачих ассиметричных складок, в ядре которых находятся нижележащие алевриты и пески глинистые (рис. 1-1a, b, c, d). Падение осевых поверхностей складок направлено по азимуту $210^{\circ}$ и углом $7-10^{\circ}$.

\section{Обсуждение и выводы}

Анализ ледникового рельефа показывает закономерное расположение отдельных форм в виде трех полос грядово-холмистого рельефа (рис. 1, A-I, II, III). Дистальная часть полос представлена грядово-холмистым и холмистым рельефом, выраженным за счёт серий чешуйчатых, реже складчатых гляциодислокаций. Проксимальная часть полос представлена в рельефе моренной грядой или цепочкой моренных гряд. Эти гряды проявляются за счёт повышенной мощности базальных тиллов, нарушенных складчатыми гляциодислокациями. Промежутки между полосами ледникового рельефа заняты участками преимущественно заболоченными понижениями и редко участками грядово-кольцевого рельефа мёртвого льда. Болотные отложения понижений залегают на озерноледниковых алевритах и песках. Поверхность заболоченных понижений осложняется относительно высокими холмами диаметром до 0.4 км и высотой до 18 м. Такие холмы зачастую являются отражением в рельефе гляциодиапиров лимногляциальных осадков или камовых флювиогляциальных аккумуляций.

Таким образом, в ходе работы установлено, что формирование ледниковых форм рельефа района работ связано с активным гляциотектоническим воздействием на рыхлые породы ложа и перенасыщенный дебрисом лёд. Хорошо выраженные в рельефе полосы грядово-холмистого рельефа, построенные преимущественно сериями чешуйчатых гляциодислокаций являются индикаторами положения активной краевой зоны одной из последних фаз деградации последнего ледниково- 
го покрова в раннем - среднем дриасе. Зону повышенной аккумуляции перенасыщенных дебрисом нижних частей ледника маркируют моренные гряды, построенные базальным тиллом и осложненные складчатыми гляциодислокациями. Участки между цепочками краевых образований заняты понижениями, поверхность которых испытывала значительное воздействие активных масс льда, что проявляется в развитии гляциоинъективных форм в виде диапиров, с озерно-ледниковыми осадками в ядре. Анализ падения гляциоструктур активного льда указывает на движение льда в районе работ преимущественно с запада на восток. С оформлением отдельных небольших языков в краевой зоне активного ледника могли происходить подвижки льда в северо-восточном и юго-восточном направлениях. Проведенное исследование позволяет сделать вывод об преимущественно фронтальном типе дегляциации этой части Кольского полуострова в позднем плейстоцене. Полученные результаты будут использованы в дальнейших работах по установлению особенностей ледникового морфогенеза и особенностей динамики последнего ледникового покрова в Кольском регионе.

Работа выполнена по теме НИР 0226-2019-0054 лаборатории №43 геологического института КНЦ РАН

\section{Литература}

1. Аболтиньш О.П. Гляциоструктура и ледниковый морфогенез. Рига: Зинатне. 1989. 284 с.

2. Геологическая карта Кольского региона. Масштаб 1: 1000 000. Гл. ред. Ф.П. Митрофанов. Апатиты. 2001.

3. Государственная геологическая карта Российской Федерации. Масштаб 1: 1000000 (третье поколение). Серия Балтийская. Лист Q-(35), 36 (Апатиты). Гл. ред. Ю.Б. Богданов. Объяснительная записка / Б.Ю. Астафьев, Ю.Б. Богданов, О.А. Воинова и др. СПб.: Картографическая фабрика ВСЕГЕИ. 2012. 456 с.

4. Евзеров В.Я. Горбунов Е.О., Колька В.В. Краевые ледниковые образования позднего дриаса в северной и центральной частях Кольского полуострова // Четвертичные отложения и новейшая тектоника ледниковый областей Восточной Европы. Апатиты. 1993. С. 26-38.

5. Евзеров В.Я., Кошечкин Б.И. Палеогеография плейстоцена западной части Кольского полуострова. Л.: Наука. 1980. 104 с.

6. Евзеров В.Я., Николаева С.Б. Пояса краевых образований Кольского региона // Геоморфология. 2000 . №1. C. $61-73$.

7. Колька В.В. Мунозерская островная возвышенность // Вестник Мурманского государственного технического университета. 1998. Т. 1. № 3. С. 79-88.

8. Лаврова М.А. Четвертичная геология Кольского полуострова. М.-Л.: Наука. 1960. 233 с.

9. Стрелков С.А., Евзеров В.Я., Кошечкин Б.И. и др. История формирования рельефа и рыхлых отложений северо-восточной части Балтийского щита. Л.: Наука. 1976. 164 с.

10. Ekman I., Iljin V. Deglaciations, the Younger Dryas End Moraines and their Correlation in Karelian A.S.S.R. and adjacent Areas // Eastern Fennoscandian Younger Dryas End Moraines. Field Conferencion. Espoo. 1991. P. 73-101. 